\title{
Vajilla metálica de época romana en los museos de Ciudad Real, Jaén y Linares
}

\author{
Joaquín Aurrecoechea Fernández *
}

\section{INTRODUCCIÓN}

La catalogación, el estudio y la publicación de los fondos museísticos que contengan materiales adscritos a la familia de los objetos metálicos, es una tarea necesaria que se está llevando a cabo desde tiempos relativamente recientes. Uniéndonos a esta dinámica, queremos dar a conocer una serie de piezas, depositadas en los museos de Jaén, Linares y Ciudad Real. Los rasgos comúnes que las definen están orientados en torno a dos puntos básicos. El primero, sería su pertenencia a un área geográfica homogénea, la antigua Oretania, región de límites algo imprecisos, pero que en líneas generales se enmarca en las actuales provincias de Ciudad Real y Jaén. $Y$, por último, todos los ejemplares que presentamos pertenecen a la categoria de la vajilla metálica.

La publicación de los recipientes metálicos en la antigua Oretania, ya fue iniciada por nosotros mismos, con un estudio dedicado a la pátera bajoimperial del yacimiento de La Bienvenida (AURRECOECHEA 1989), al que siguió otro, centrado en los apliques de situla (AURRECOECHEA Y ZARZALEJOS 1990). El panorama se hallaba casi íntegro, con los estudios vinculados a dos de las entidades urbanas de la zona: Cástulo (BLAZQUEZ 1984) Y SISAPO (AURRECOECHEA et alii 1986), más alguna noticia suelta,

\footnotetext{
* Universidad Autónoma de Madrid.
} 
como la referida al aplique de la colección Muñoz, hallado en el término municipal de Cazorla (BELTRAN FoRTES et alii 1989, 856). Faltaban, por tanto, los especímenes que aquí presentamos para rematar este capítulo de la arqueología oretana.

Las motivaciones que nos impulsaron a la redacción de este artículo fueron, por una parte, el que casi todas las piezas se hallaban inéditas, y por otra, las conclusiones que podríamos establecer a tenor del conocimiento de las mismas, pues con ellas y las ya conocidas, tenemos la suficiente base como para crear una investigación globalizadora de la temática en cuestión.

De la tónica aludida con anterioridad, sólo se apartan tres ejemplares ya divulgados en sendos artículos, pero que retomamos debido a su insuficiente publicación. Nos referimos al mango hallado en Los Castellones de Ceal (Jaén), publicado erróneamente como instrumento médico (FERnández Chicarro 1956, 101-121, fig. 21); a una de las sítulas de la villa Plaza de Armas (Bruñel, Jaén) (DEL Nido 1964-65, lám. 66, 4), de la que sólo se ofreció una fotografía; y a un cazo de La Bienvenida (Almodóvar, Ciudad Real), para el que contamos con nuevos elementos de valoración (AURRECOECHEA et alii 1986, 267, lám. 4, 8).

El trabajo se estructura en tres bloques principales. El primero está reservado a la procedencia de los materiales, mientras que el segundo recoge el catálogo organizado por grupos y el estudio individualizado de cada pieza. Por último, se ofrece una síntesis general, que integran los datos conocidos hasta ahora, más los nuevos aquí aportados.

\section{PROCEDENCIA DE LOS MATERIALES}

El grueso de los materiales recogidos en este estudio carecen de un contexto arqueológico definido, siendo algunos de ellos producto de hallazgos aislados y otros fruto de donaciones particulares a los museos que tratamos. Sólo en el caso de la villa «Plaza de Armas» y en el de La Bienvenida, nos encontramos ante yacimientos conocidos de forma científica, aunque lamentablemente para ambos, carecemos de referencias estratigráficas.

La Bienvenida se halla situada en la finca de igual nombre, en el término municipal de Almodóvar del Campo (Ciudad Real), en pleno centro del Valle de Alcudia. Las primeras excavaciones científicas llevadas a 
Vajilla metálica de época romana en los museos de Ciudad Real, ...

Cabo en su terreno se realizaron en 1953, pero de ellas apenas tenemos noticias, salvo el descubrimiento de un gran patio porticado o peristilo. Fue en 1980 cuando se planteó la primera de una serie de campañas sistemáticas, dirigidas por Carmen Fernández Ochoa y Alfonso Caballero Klink, y que han puesto al descubierto los restos de una importante ciudad (CABAllero y Fernandez OCHOA 1981, 233 y ss.). En 1982 se realizó una nueva campaña en dos zonas, una alrededor del patio porticado y otra en la zona denominada "Hoyo Santo", que se ubica al SW del peristilo. El fruto de las excavaciones iniciales manifestó una serie de estratos superficiales muy alterados, en los que se recogieron materiales que demuestran la continuidad del hábitat, desde fines del siglo $\mathrm{v}$ a. $\mathrm{C}$., hasta la romanidad tardia. Básicamente, las piezas publicadas ya en su momento, más la que incorporamos en el presente estudio son producto de estas campañas, no contando para ellas, por tanto, con un marco estratigráfico concreto. Desde 1984 se han sucedido, ininterrumpidamente, nuevos trabajos sobre el terreno. Constatándose, durante el siglo IV d. C., el reaprovechamiento de estructuras anteriores mediante la amortización de sus materiales constructivos, y la existencia de una muralla (Fernández Ochoa y Caballero 1988, 201 y ss.).

Aunque en los primeros momentos de la excavación se pensó que "La Bienvenida" podría ser el Carcuvium del Itinerario, actualmente la posibilidad de que dicho yacimiento sea la antigua Sisapo parece fuera de dudas. Esta deducción se ha hecho no sólo a través de los datos arqueológicos, que serian la inscripción con la leyenda (S)ISAPON(E) (FERNANDEZ OCHOA et alii 1982-83, 211 y ss), sino contando también con las posibilidades económicas del emplazamiento y las noticias que de ellas se encuentran en las fuentes latinas para la ciudad de Sisapo.

El yacimiento "Plaza de Armas", se encuentra ubicado en el cortijo homónimo, perteneciente al término municipal de Quesada (Jaén). Descubierto en 1965 se realizó una amplia campaña de excavación, por Rafael del Nido, cuyo fruto es la puesta a la luz de los restos de una "villa" romana y de un aula con doble ábside, que inmediatamente se interpreta como basílica. La memoria de dichos trabajos, desgraciadamente, es excesivamente sucinta y escueta (DEL NIDO 1964-65, 203 y ss., lám. 4546). En 1967 se retoma la excavación, ahora dirigida por un nuevo equipo de investigadores (Arribas, Riu y Palol), con la misión primordial de limpiar y análizar los restos constatados. Confirmándose la existencia de una gran «villa» del Bajo Imperio, que sufre ampliaciones sucesivas. Constructivamente se advierten dos etapas claras. Un establecimiento de pequeño atrio con impluvium situado al lado $\mathrm{N}$ del conjunto y un peristilo no muy ámplio, al sur de dicho atrio, que fue posteriormente cortado por 
un gran muro recto, en dirección $\mathrm{E}-\mathrm{O}$, de la fachada $\mathrm{N}$ del aula dobleabsidiada. Así el peristilo, cubierto de mosaicos, es cortado en su mitad sur para superponer la mencionada aula, que conserva los pavimentos del antiguo recinto (PALOL Y SOTOMAYOR 1972, 376). La decoración musivaria del lado oeste del peristilo se puede datar en el siglo III o quizá en el siglo IV d.C. (BLÁZQUEZ 1981, 63). Las posteriores campañas, de 1968 y 1970, dirigidas por: Arribas, González Navarrete y Sotomayor, se centran en el área sur de la gran aula, constatándose frente a ella un patio rectangular, rodeado por un corredor abierto y pavimentos de opus signinum asentados directamente sobre el mosaico de la "villa" anterior. Alrededor del corredor, se disponen una serie de habitaciones, en las que aparecieron algunos objetos metálicos como: hoces, sítulas, cencerros, cizallas, etc. (PALOL Y SOTOMAYOR 1972, 380). Todo este conjunto parece realizado a lo largo del siglo IV d.C., e incluso en fechas posteriores.

Para Fdez. Castro, se trataba de una construcción de carácter señorial (FERnÁNDEZ CASTRO 1982, 101). La identidad del aula dobleabsidiada no ha sido resuelta. Dicha estancia pudo tener un carácter profano, vista la ausencia de elementos religiosos cristianos, por lo que quizá se trata de una habitación de recepción. El problema se complica si tenemos en cuenta que la construcción puede estar inconclusa.

En el presente estudio recogemos los materiales depositados en las vitrinas del Museo de Jaén, pertenecientes mayoritariamente a las primeras campañas. El resto de las piezas se hallan en los fondos de esta institución, todavía a la espera de su restauración y consolidación, y son el objeto de una tesis doctoral que actualmente se elabora.

\section{CATÁLOGO Y ESTUDIO DE LOS MATERIALES}

A continuación ofrecemos el inventario de las piezas recogidas en el ámbito oretano. Éstas han sido agrupadas en relación a su funcionalidad, conformando una serie de grandes apartados. 
CUENCOS

Nüm. 1 (fig. 1, 1)

Procedencia: Desconocida, depositado en el Museo de Jaén.

Descripción: Cuenco semiesférico de plata, con base en anillo. Borde recto, que forma una moldura exterior. Técnicamente, parece tratarse de un producto de fundición. Mide 7,2 cm de diámetro en el borde y $3,7 \mathrm{~cm}$ de altura.

Núm. 2. (fig. 1, 2)

Procedencia: Desconocida, depositado en el Museo de Jaén.

Descripción: Sensiblemente idéntica a la anterior, pero con la moldura del borde en el interior. Mide $7,2 \mathrm{~cm}$ de diametro en el borde y $3,7 \mathrm{~cm}$ de altura.

Estudio: Los números uno y dos de nuestro inventario, fueron hallados juntos, cobijando en su interior un tesorillo de denarios republicanos. Están realizados de tal forma que encajan entre si, a través del labio, formando un solo recipiente herméticamente cerrado.

Muchos son los tesoros aparecidos en el territorio de la antigua Oretania (La Alameda, Perotito, Los Villares, Torre de Juan Abad, Mogón, Mengibar, etc.), no en vano la zona gozaba de gran prestigio en la antigüedad, como productora de plata. En la mayoría de ellos se encuentran monedas de época republicana, gracias a las cuales, se ha determinado la fecha de ocultación y por extensión, la cronología relativa de las piezas metálicas. Los cuencos que tratamos siguen esta tónica general, aunque lamentablemente carecemos de la apoyatura numismática, ya que el tesorillo que los acompañaba se encuentra en paradero desconocido.

En ninguno de los tesoros referidos anteriormente, hallamos vasos semejantes a estos del museo de Jaén. El tipo más extendido, entre estos ocultamientos, es el cuenco cónico que carece de pie, denominado mastos, característico del período helenístico tardío (STRONG 1966, 108109), muy abundante en el resto de España y en los Balcanes. 

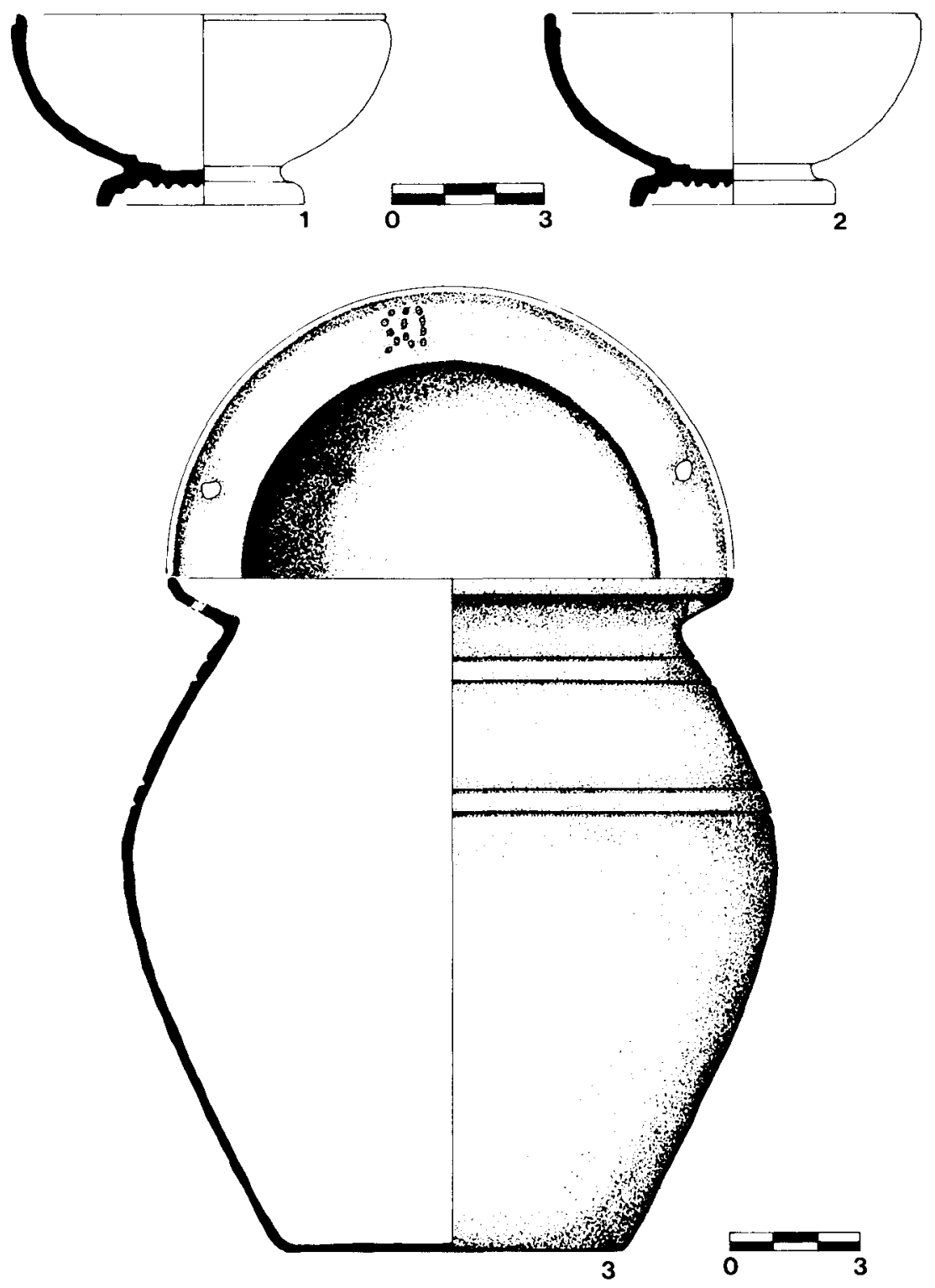

Fig. 1: Núm. 1 y 2: Cuencos de plata del Museo de Jaén. Núm. 3: Recipiente del Museo de Linares. 
Vajilla metálica de época romana en los museos de Ciudad Real, ...

Los cuencos semiesféricos con pie, comienzan a utilizarse en las postrimerias del helenismo, siendo, en principio, formalmente muy sencillos. En esta descripción encajan los dos cuencos giennenses más otros tres de Tívoli, siendo estos últimos los paralelos más próximos para las piezas hispanas. Los ejemplares itálicos se datan a mediados del siglo I a. C. y ostentan, como dato anecdótico, una inscripción que indica quién era su poseedora (Sattia) asi como el peso de los vasos (OLIVER 1977, 107, núm. 66-68).

En el tesoro de Arcisate (alrededor del 75 a. C.) encontramos un cuenco de este tipo, con moldura interior, pero cuyo pie se halla desarrollado (WALTERS 1921, 32, lám. 17, núm. 127). Perotito ha proporcionado una gran copa con decoración moldeada, cuyo receptáculo superior reúne estas características (Álvarez 1954, 303, lám. 35), junto a un cuenco sin pie (Álvarez 1954, 303, lám. 36).

Esta forma siguió usándose en tiempos del imperio, como lo demuestra el hallazgo de Lameira Larga (Portugal), cuya cronología oscila entre el siglo $1-\| \mathrm{d}$ d. C., según parece derivarse de la pátera que acompañaba el conjunto (García y BELLIDo 1949, 461). Formarían el tipo «9" de Drexel (DREXEL 1909, 176-235, lám. 6, núm. 9), compuesto por cuencos semiesféricos con pie, ya de época imperial, aunque de clara reminiscencia del periodo anterior. Uno de los ejemplares más tardíos seria el de Xanten (siglo III d. C.), en cuyo fondo se grabó la imagen de un pez (HERBERT Y KAUFMANN-HEINIMAN 1984, 171, lám. 75).

También conocemos este perfil en recipientes de bronce, pero sin pie, como los cuencos tipo “69" y “70" de Eggers (EGGERS 1951, lám. 8 , núm. 69 y 70 ), siendo una forma muy popular desde comienzos del imperio, hasta el siglo IV d. C. (SAKAR 1970, 64).

CALDEROS

Núm. 3 (fig 1, 3).

Procedencia: Donación de D. J. L. Sobrino Vicente al Museo de Linares (Jaén).

Descripción: Recipiente de bronce de paredes curvas y borde exvasado, decorado mediante cuatro acanaladuras que recorren el galbo del 
vaso. Cuatro perforaciones circulares simétricas, servirian para la inserción de sendos apliques. En la parte interna del borde conserva una inscripción punteada, con las letras "SII". Es producto de fundición. Mide $13,4 \mathrm{~cm}$ de diámetro en el borde y $15,6 \mathrm{~cm}$ de altura.

Estudio: Se trata de un aenum correspondiente a la familia denominada genéricamente östland (BOESTERD 1956, 40), en concreto pertenece a la rama de los calderos que presentan la pared curva y el borde exvasado poco profundo. Estos recipientes son recogidos por Eggers con el número 40 de su clasificación (EGGERS 1951, Fig. 6, núm. 40) y por Radnoti con el 49 (RADNOTI 1938, Fig. 10, núm. 49). Para Ekholn, la forma de la boca estaría en función de una cubierta de madera, de la que han quedado restos procedentes de Brokaer (Dinamarca). Son manufactura italiana del siglo $1-\| \mathrm{d}$. C.

La mayor difusión de ejemplares la encontramos en Germania y zonas extralimitáneas, apareciendo profusamente en los enterramientos, especialmente en Bohemia (Trebusice, Lovosice, etc.).

Del nutrido número de piezas existentes (HEINZ 1980, 634-638, fig. 1 y 3), manifestamos las analogias del cubo de Linares con otros dos depositados en Nijmegen. Uno de ellos presenta sendas líneas decorativas en el galbo, lo que no es muy común (Boesterd 1956, 40, fig. 5, núm. 125), y el otro posee una inscripción punteada que versa T. M IIII ARI (BOESTERD 1956, 41, lám. 18, núm. 131).

Num. 4 (fig. 2, 4).

Procedencia: Cortijo Plaza de Armas (Bruñel, Jaén), depositado en el Museo de Jaén.

Descripción: Recipiente de bronce de forma bitronconcónica, con borde exvasado que presenta dos orificios simétricos. Fondo plano. Posiblemente producto de fundición. Mide $8,9 \mathrm{~cm}$ de diámetro en el borde y $8,5 \mathrm{~cm}$ de altura.

Estudio: Pequeño aenum de tipo östland, perteneciente a la categoria de las que posee un cuerpo ancho y generalmente convexo. La datación de estos vasos es similar a la ofrecida por la variante reseñada con el número de inventario anterior, aunque algunos autores alargan la cronología del tipo que nos ocupa hasta el siglo ill d.C. (SAKAR 1970, 64). 
Vajilla metálica de época romana en los museos de Ciudad Real, ...

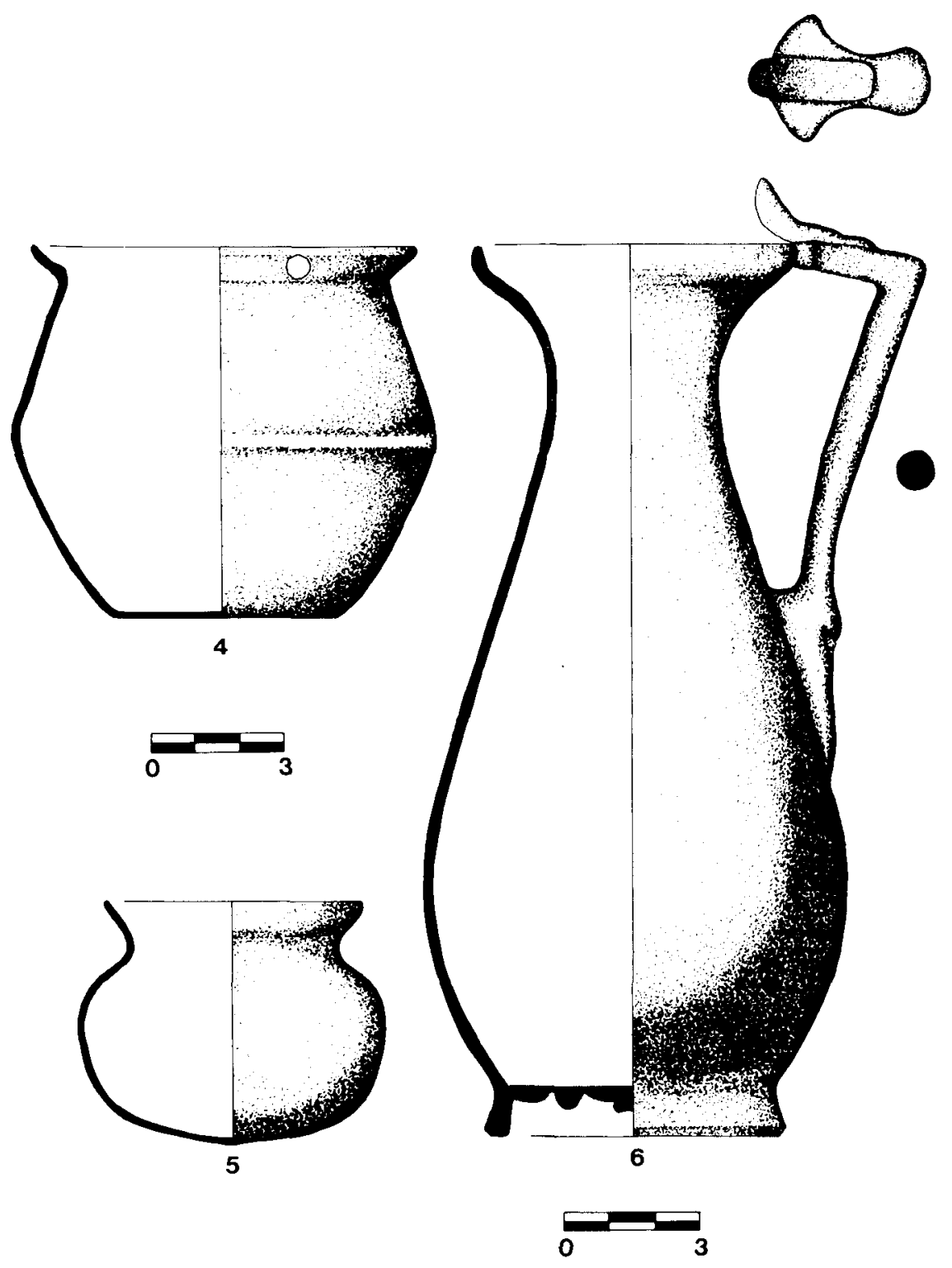

Fig. 2: Núm. 4: Recipiente del Cortijo Plaza de Armas (Jaén).

Núm. 5: Vaso del Museo de Linares.

Núm. 6: Jarra hallada en Jodar (Jaén). 
Una pieza muy semejante procede de Winseling (BoESTERD 1956, 42, fig. 5 , núm. 138).

VASOS

Núm. 5 (fig. 2, 5).

Procedencia: Desconocida, depositado en el Museo de Linares (Núm. inv. 628).

Descripción: Recipiente de cobre con paredes sinuosas, realizado mediante martilleado de un disco de cobre. Mide $6 \mathrm{~cm}$ de diámetro en el borde, $5,7 \mathrm{~cm}$ de altura y $0,1 \mathrm{~cm}$ de grosor.

Estudio: No han sido hallados paralelos exactos para esta pieza, aunque su reducido tamaño, nos induce a pensar en un recipiente destinado a la función de vaso.

JARRAS

Núm. 6 (fig. 2, 6)

Procedencia: Jodar (Jaén), depositada en el Museo de Jaén.

Descripción: Jarra de bronce de cuerpo ovoide y borde exvasado, con labio recto. La base está compuesta por un disco macizo, con molduras interiores que originan círculos concéntricos. Asa recta, decorada en la parte terminal mediante un motivo irreconocible, debido al desgaste. La unión del asa con la boca del recipiente, se hace mediante una gruesa hoja que se inclina hacia atrás, para servir de apoyo al dedo pulgar. Tanto el fondo como el asa, son producto de fundición, mientras que el resto del vaso ha sido conseguido mediante martilleado sobre lámina. Mide $7 \mathrm{~cm}$ de diámetro en la boca y $19,1 \mathrm{~cm}$ de altura. 
Estudio: Nos hallamos ante un urceus (HILGER 1969, 299-300). En el MAN de Madrid se conserva un ejemplar de cuerpo oval (BLÁZQUEZ 1960, 201, fig. 4, núm. 6), de tipologia algo distinta al nuestro, pero que nos sirve para ilustrar el tipo.

La pieza de Jodar se inscribe en un grupo bastante amplio de jarras, caracterizado por la heterogeneidad. Todas ellas poseen unos valores comunes, como son la forma del cuerpo y la parte superior del asa en forma de hoja vuelta (BOESTERD 1956, 77, núm. 276). Aunque dentro de estos parámetros, el cuerpo puede ser algo más oval, como en el vaso de Bonn (Menzel 1986, 195, lám. 67, núm. 535), o el asa puede presentar una elaborada decoración, incluso llegando, como en el jarro de Poulseur, a representar escenas de corte dionisíaco o metróico (FAIDER-FEYTMANS 1979, 175-176, lám. 136, núm. 359), caso también repetido en el de Martigny (LEIBUNDGUT 1980, lám. 163, núm. 182). También se conoce la existencia de otros especimenes más ricos, como los ejemplares de Saint-Romain-en-Gal, en donde el bronce se recubrió de una fina película de plata (BOUCHER Y TASSINARI 1976, 146, núm. 187 y 188).

Este tipo de piezas tendría su origen en producciones italianas del siglo I d.C., para pasar en el siglo II d.C. a talleres provinciales, que continuarian con la fabricación hasta mediados del siglo III d.C. (MENZEL 1986, 195).

Un urceus formalmente semejante al nuestro, de producción provincial y fechado en el siglo III d.C., procede de Germania (MENZEL 1966, 37-38, lám. 46, núm. 67), si bien no tiene círculos concéntricos en su base. Jarros con fondo realizado en disco aparte y círculos concéntricos, los encontramos en Atnwerpen (producción campana de época flavia) (FAIDER-FEYTMANS 1979, 163, lám. 118, núm. 322), Augst (importación italiana del siglo I d.C.) (KAUFMANN-HEINIMANN 1977, 143-144, lám. 156, núm. 247) y Lyon (fabricación provincial del siglo II-III d.C.) (BOUCHER Y TASSINARI 1976, 144, núm. 184).

Las peculiaridades intrínsecas de la pieza de Jaén, nos hacen postular que se trate de un producto provincial, fechado posiblemente en el siglo in d.C.

Núm. 7. (fig. 3, 7).

Procedencia: Cortijo Plaza de Armas (Bruñel, Jaén), depositado en el Museo de Jaén. 


$$
\Leftrightarrow
$$


Descripción: Vaso de bronce de cuerpo bicónico y alto cuello en forma de cono truncado, que conserva una cinta de plomo alrededor. Borde vuelto al interior. La base, hoy separada, es una lámina discoidal, que estuvo soldada al pequeño receptáculo obtenida al exvasar la parte inferior del galbo. La ausencia de soldaduras en el recipiente, indica que se obtuvo mediante el martilleado de una pieza fundida enteriza con forma de tubo, que se moldeó por estirado y repujado con martillo. El acabado exterior de la pieza se consiguió al alisarla con torno, por compresión y fricción. Mide $3,8 \mathrm{~cm}$ diámetro del borde y $19 \mathrm{~cm}$ de altura.

Estudio: Se trata de una lagoena (HILGer 1969, 203-205). Pocos son los paralelos que podemos referir para esta pieza, perteneciendo todos ellos al ámbito hispano. Un denominador común, sugiere una fabricación provincial, especializada en jarras de cuerpo bicónico y alto cuello troncocónico, con el fondo constituido por una chapa encajada en el saliente de la base, realizadas mediante el sistema comentado en la descripción. Los ejemplares de Conímbriga (ALARCAO 1979, 154, lám. 37, núm. 15 y 16), abogan por la posibilidad de una embocadura fundida aparte y la existencia de un asa, si bien, en ninguno de los vasos llegados hasta nosotros se han conservado estos elementos. Estas características, acercarian nuestro grupo al tipo de jarras "blechkannen", de la que presentamos en el número siguiente del catálogo una muestra.

De Fojo das Pombas, procede una lagoena cuyo cuello presenta un saliente anular que fue ejecutado, primero por repujado y después por realce (De Alburqueroue e CASTRO 1962, 174, fig. 6, núm. 4), y que produce un efecto muy parecido a la cinta de plomo, que rodea el cuello del ejemplar que aquí ofrecemos.

El paralelo más exacto lo encontramos en Carrascosa de Haro, sólo que el labio, en este caso, es exvasado ( FUENTES 1980, 120-121, fig. 22). Fuentes lo vincula con el tipo "11» de Caballero Zoreda, integrado por jarras de cuerpo globular y cuello troncocónico (CABALLERO 1974, 138 , fig. 35 , núm. 2), creando un subtipo “ 11 B» que englobaría aquellas de galbo troncocónico carenado (FUENTES 1980, 131). Por nuestra parte, creemos que el grupo aqui descrito tiene una entidad propia, que le hace merecedor de configurar un tipo aparte, a la espera de confirmación cronológica, posiblemente dentro de los parámetros temporales de los siglos III-IV d.C, pues la datación en el siglo II d. C., del ejemplar de Valongo es discutible.

Queremos hacer hincapié, por último, en las similitudes que hemos podido observar entre esta forma y las jarras "blechkannen" halladas en Panonia, fechadas desde la mitad del siglo III d. C., hasta el siglo IV. Bas- 
te citar como ejemplo de esta analogía, el ejemplar hallado en Szalacska asociado a monedas de Galieno (RADNOTI 1938, 154). La mayor diferencia entre ellas, es que los ejemplares panónicos suelen estar confeccionados en hierro martilleado. Para Raev, este tipo de «blechkannen» llegaría al Occidente de Europa en fechas algo más tardías, hacia finales de la cuarta centuria (RAEV 1976, 158). A esta fecha apuntaría la jarra hallada en el sarcófago $E$ de Köln-Müngersdorf, cuyo cuerpo se asemeja mucho al nuestro (FREMERSDORF 1933, 101). El ejemplar perteneciente a la sepultura de Täbingen, de formas más redondeadas, se fecha entre finales del siglo $v$ d. C. hasta inicios del siglo vi d.C. (WEECK 1932, 61). Cabe preguntarse si los recipientes individualizados con el número 11 de la clasificación relativa a la vajilla metálica tardorromana, serian la derivación más occidental de las jarras «blechkannen» expuestas.

Núm. 8. (fig. 4, 8).

Procedencia: Desconocida, depositada en el Museo de Jaén.

Descripción: Boca de jarra, maciza y realizada en bronce, fundida simultáneamente con el asa. En la unión de estos elementos, dos pequeños salientes perforados, servirían para soportar un eje que articulara la tapa, actualmente separada. La tapa conserva un elemento de prehensión, consistente en un vástago cilíndrico sinuoso. El asa, muy elaborada, presenta un espolón en la parte superior, para el apoyo del dedo pulgar, y dos perforaciones en las que, posiblemente, se dispondría otro elemento que asegurara la fijación al cuerpo del vaso. Mide $16,2 \mathrm{~cm}$ de longitud máxima.

Estudio: Corresponde a un vaso, denominado "blechkannen", categoría que engloba a las jarras realizadas en una fina lámina de metal, con boca y asa macizos, fundidos en una sola pieza.

La historiografia de este tipo de recipientes ha sufrido una lenta evolución. El primer investigador que las reunió en un grupo, sistematizando las de Panonia, fue Radnoti (RADNOTI 1938, 151-155). Posteriormente Eggers excindió las producciones galo-romanas, asignándoles el número "128" de su clasificación (EGGERs 1951, lám. 11, núm. 128). Raev enriqueció la ya larga lista de ejemplares, con el material de las provincias del Danubio y de la Europa Oriental, sentado las bases para el conocimiento de este tipo de recipientes (RAEV 1976, 155-162). 
Vajilla metálica de época romana en los museos de Ciudad Real, ...
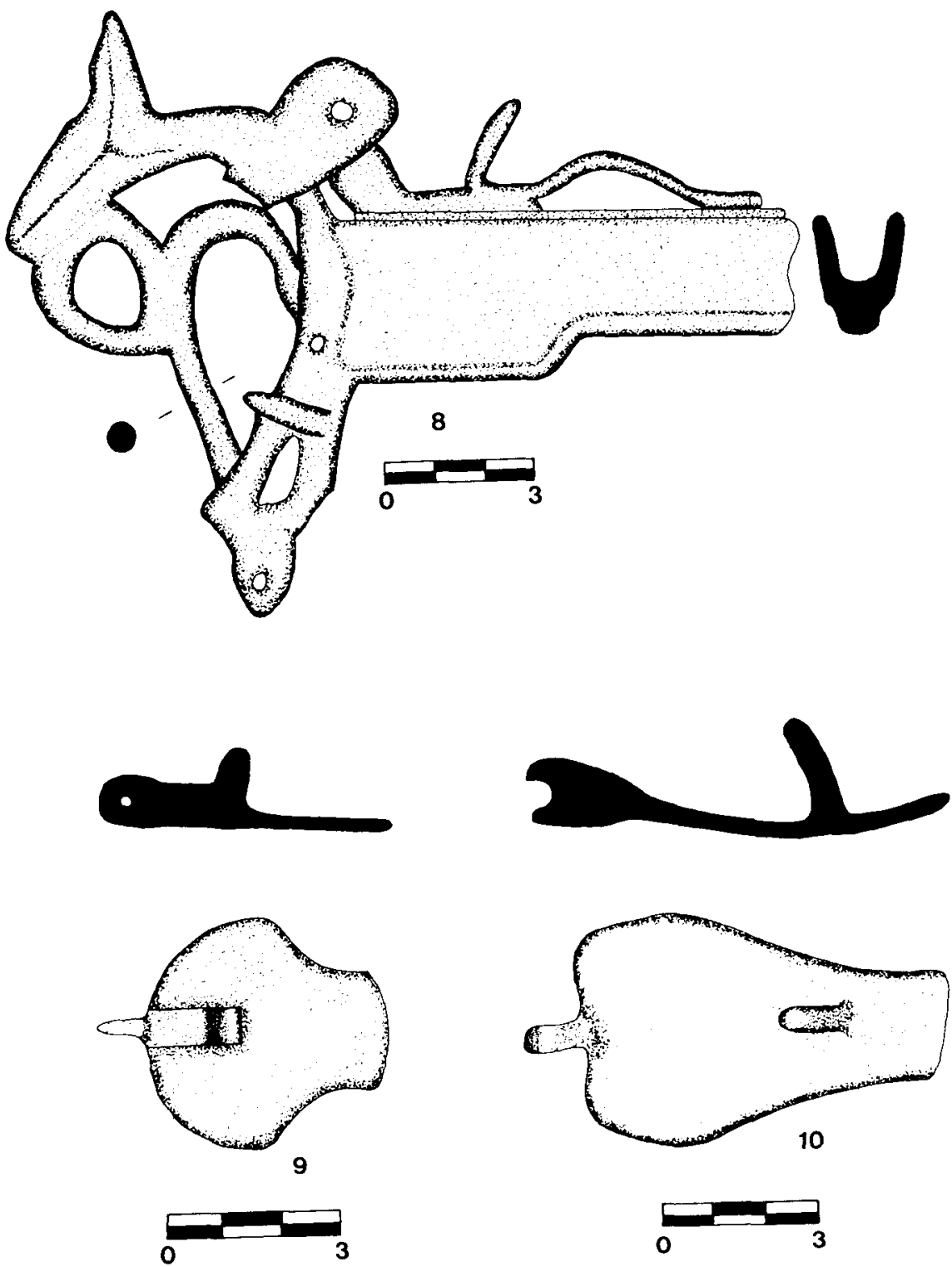

Fig. 4: Núm. 8: Boca de jarra del Museo de Jaén.

Núm. 9: Tapa del Museo de Jaén.

Núm. 10: Tapa de Porcuna (Jaén). 
Cronológicamente contamos con tres etapas sucesivas dentro de la evolución de estas jarras. Las más antiguas responderian a formas griegas, cuya tradición se continúa en los siglos । a.C. al I d.C. por artesanos itálicos, de los cuales derivarían a comienzos del siglo ॥ d.C. la fabricación de "blechkannen" en otras provincias del Imperio.

Para Tassinari, el origen de este tipo, de producción provincial (siglo II-III), estaría motivado en una forma campana, muy común en el siglo I d. C., consistente en jarras globulares con asas recurvadas y charnela para tapa. Sin embargo, Raev opina que los antecedentes italianos, de la primera centuria, se encuentran basados en los modelos procedentes de necrópolis prerromanas del siglo vi-III a. C. que fueron realizados por artesanos griegos llegados a Italia, y que con el tiempo originaron el vaso romano. Estas jarras italianas, elaboradas ya por la cultura romana, serían las integrantes de su primer tipo. Exponentes de estos ejemplares tempranos del siglo I d. C., los encontramos en los productos importados de Doorwerth, Catalka y Mochenwangen (MILLER 1884, 38-40)

Para Raev existen dos tipos de «blechkannen» provinciales. Los del primer tipo, recogidos por Eggers con el apelativo de galo-romanos, serian aquellos de cuerpo redondeado, generalmente bicónico, cuyos hombros inclinados se estrechan en un cuello de poca altura. El cuerpo está ejecutado sobre una delgada lámina de bronce, donde pueden apreciarse las huellas del torno. El asa es fundida aparte, junto con el borde, poseyendo este último una tapa móvil. A este tipo estaria adscrito el ejemplar giennense que tratamos.

Temporalmente para estos productos contamos, para los realizados al sur del limes, Rhin y provincias danubianas, con el término ante quen del 259-260 d. C., época en que son destruidos los campamentos militares de esta región. El período de fabricación mayoritaria estaría situado entre los siglos II-III d. C. En la Galia, el jarro de Landency está datado a mediados del siglo III, y el de Martigny en la primera mitad de dicha centuria. En Germania las jarras del primer tipo también cumplen los límites del siglo II-III, cronología constatada asimismo en Panonia (BOESTERD 1956, 70-71, lám. 11, núms. 257 y 258). En los territorios limítrofes del Imperio también aparece esta forma, contando precisamente para esta zona con la fecha más tardía en una sepultura de Cejkov, fechada desde fines del siglo III a comienzos del siglo IV (RAEV 1976, 156).

El segundo tipo, denominado tracio, también está hecho sobre una lámina de metal, pero no presenta torneado posterior. El cuerpo es más estrecho hacia el fondo, siendo los hombros casi horizontales y el cuello embutiforme. Suelen ostentar una gruesa asa de hierro (RAEV 1976, 155- 
156). Su centro de producción más antiguo se encuentra en Tracia, siendo un hallazgo frecuente en las sepulturas nómadas de las estepas de la Europa Oriental a fines de la primera centuria (RAEV 1976, 158). En Panonia el tipo aparece a mediados del siglo 111 d. C. A las provincias occidentales llegan acompañando a las grandes invasiones, apareciendo en las tumbas de los siglos iv y $\vee \mathrm{d}$. C.

Centrándonos en la pieza de Jaén, destacamos de entre los paralelos más cercanos los de Aube (TASSINARI 1975, 69, lám. 35, núm. 180); Côte d'Azur (que contenía un tesorillo fechado en época de Aureliano) (GOUDINEAU 1981, 538, fig. 14); Lyon (asociado a un tesorillo de finales del siglo III d. C.) (BOUCHER Y TASSINARI 1976, 151-152, núm. 193), y Vienne (BOuCHER 1975, 138, núm. 255). Ahora bien, en todos los ejemplares publicados, no se constata el extenso desarrollo decorativo que presenta el asa de Jaén. El caso más cercano es una jarra procedente de Chalon-sur-Saóne (BOUCHER Y TASSINARI 1976, 153, núm. 194), aunque no llega a ser tan complicada. Otro rasgo significativo es el perfil de la boca, que en su parte superior es recto, encontrándose solamente en la pieza que presentamos y en otra de Szekszárd (RADNOTI 1938, lám. 52 , núm. 4). El resto ostenta la zona terminal levantada, lo que le confiere la apariencia de pico vertedor.

En Hispania han sido halladas también "blechkannen» del tipo galoromano en Conímbriga (ALARCAO 1979, 154, lám. 37, núm. 12), Mérida (Nogales 1990, 113, fotografía en pág. 110) y en el pecio del Cabo de Higer (Fuenterrabía, Guipúzcoa) (URTEAGa 1988, 111-122). El Museo Arqueológico de Oviedo cuenta con otro ejemplar descontextualizado (EsCORTELL 1975, lám. 97). Del grupo de bronces de la colección Salaman$\mathrm{ca}$, depositados en el MAN de Madrid, procede una jarra con estas características (THOUVENOT 1927, 92-94, núm. 467). Por último, inéditas son las de Arganda y Velilla, en la provincia de Madrid, y Seseña en la de Toledo, de las que nos ocuparemos en un próximo estudio.

Núm. 9 (fig. 4.9)

Procedencia: Desconocida, depositada en el Museo de Linares (Jaén).

Descripción: Tapa de jarra en bronce, con apéndice superior para sujeción, y orificio para su unión mediante charnela con la boca del reci- 
piente. Se trata de un producto de fundición. Mide $4,9 \mathrm{~cm}$ de longitud máxima, $4 \mathrm{~cm}$ de ancho máximo y $1,4 \mathrm{~cm}$ de grosor máximo.

Estudio: Tapa de jarro «Blechkannen» en bronce, para la que se podrían citar múltiples paralelos foráneos (BOESTERD 1956, 70, lám 11, núm. 249 , etcétera), por lo que simplemente reseñamos otra aparecida en suelo hispano; la de Bílbilis (ORENSANz 1972, 149-151).

Núm. 10 (fig. 4, 10).

Procedencia: Porcuna (Jaén), depositada en el Museo de Jaén.

Descripción: Semejante a la anterior, aunque de mayor tamaño e incompleta. Mide $8,2 \mathrm{~cm}$ de longitud y $4,5 \mathrm{~cm}$ de ancho máximo.

Estudio: Ver el estudio de las piezas núm. 8 y 9.

SÍTULAS

Núm. 11 (fig. 5, 11).

Procedencia: Cortijo Plaza de Armas (Bruñel, Jaén), depositada en el Museo de Jaén.

Descripción: Cubo carenado de hierro, de paredes rectas. Fabricado a partir de una lámina doblada y soldada sobre si misma. Asa recortada sobre hoja y terminada en estilizadas cabezas de pato. Mide $14 \mathrm{~cm}$ de diámetro y $14,2 \mathrm{~cm}$ de altura.

Estudio: El ejemplar giennense se aleja, sensiblemente, del tipo característico de situla hispana, al menos de las que mejor conocemos, las tardias. Generalmente son de cuerpo casi cilindrico, fondo esférico y base plana con ligero umbo, borde doblado hacia afuera y dos pestañas triangulares para la inserción del asa. Exponentes de ellas tenemos en Aldea de San Esteban (PALOL 1970, 192, fig. 2), Torre dos Namorados (MARQUÉs 1969, 71, lám. 5, núm. 1), Nuez de Abajo, Ventosa de Pisuerga, 

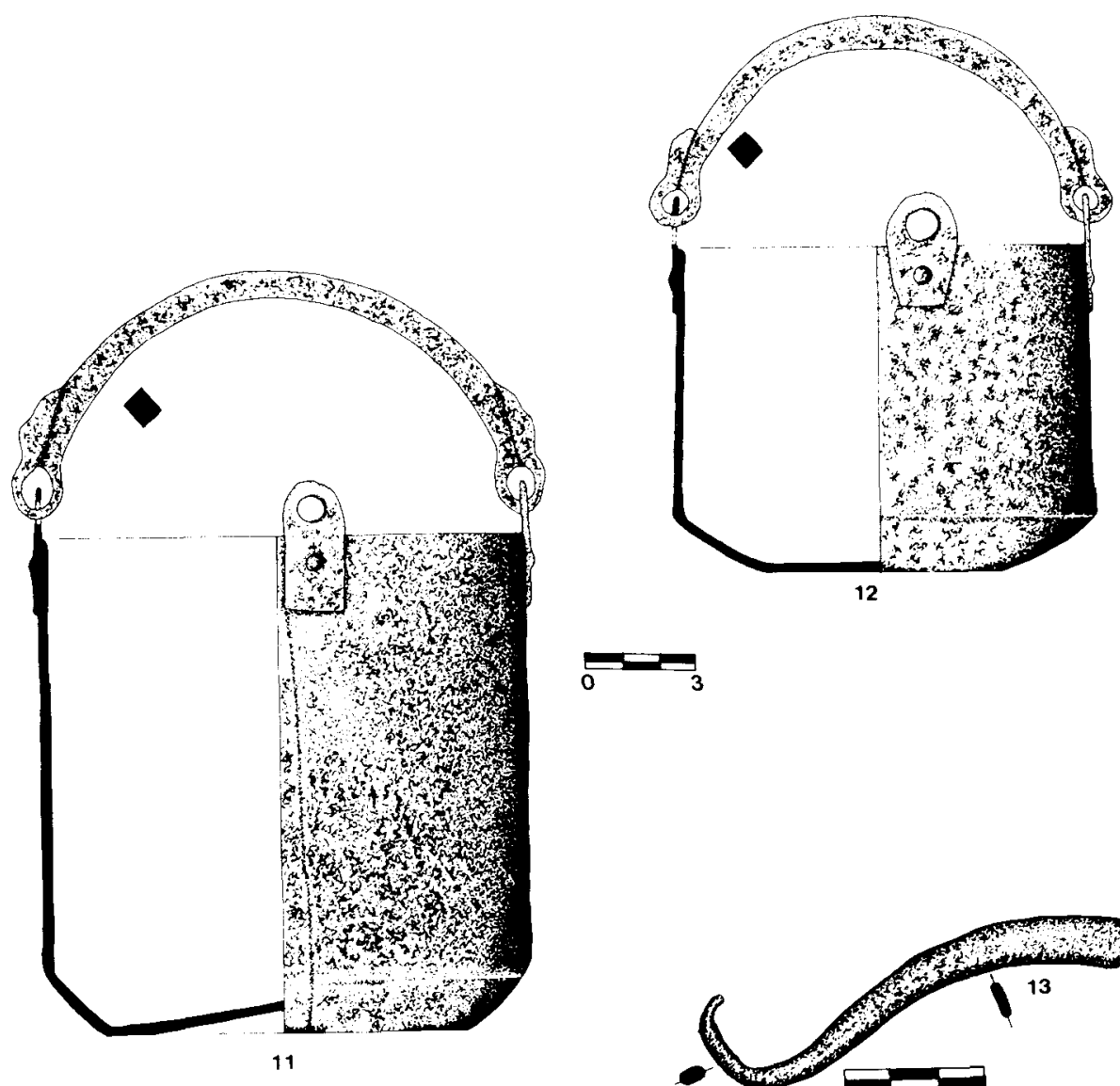

Fig. 5: Núm. 11: Sítula del Cortijo Plaza de Armas (Jaén). Núm. 12: Sítula del Cortijo plaza de Armas (Jaén). Núm. 13: Asa de sítula de La Bienvenida (Ciudad Real). 
etcétera. Fechadas todas ellas en el Bajoimperio y realizadas sobre cobre/bronce.

La pieza más cercana que hemos constatado es la procedente de Fojo das Pombas (De Alburquerque e Castro 1962, 174, fig. 6, núm. 5 ), inserta en un marco cronológico correspondiente al siglo ॥ d. C., no del todo confirmado.

Los apliques de la situla de Jaén pertenecen al tipo C. III de Delgado (Delgado 1970, 28, fig. 3, núm. 21). Elementos semejantes los encontramos en un pequeño bote de cobre forrado de hierro, hallado en la sepultura 17 de la necrópolis tardorromana de Las Merchanas (MALUQueR 1968, 125, fig. 10), en el acetre, de época altoimperial, de Sant Josep (Rosas 1980, 36, fig. 4, núm. 36), aunque este último es un aplique soldado al vaso y no remachado, y en la sítula de Hornillos del Camino (MONTEVERDE 1945, 339, fig. 1 a 4).

El asa es del tipo A. I de Delgado (Delgado 1970, 33), forma muy común en Hispania, y de la que trataremos más extensamente en otro capítulo del inventario.

Núm. 12 (fig. 5, 12).

Procedencia: Cortijo Plaza de Armas (Bruñel, Jaén), depositada en el Museo de Jaén.

Descripción: Semejante a la anterior. Mide $11,7 \mathrm{~cm}$ de diámetro en el borde y $9,3 \mathrm{~cm}$ de altura.

Estudio: Idéntico al precedente.

Núm. 13 (fig. 5, 13).

Procedencia: La Bienvenida (Núm. inv. BV/82/2/1302), depositada en el Museo de Ciudad Real.

Descripción: Fragmento de asa en bronce, fabricada a partir de una lámina rectangular, de ángulos oblongos, a la que se le dobló su parte terminal. Mide $9,5 \mathrm{~cm}$ de longitud máxima y $1 \mathrm{~cm}$ de ancho máximo. 
Estudio: Corresponde al tipo “A.ll» de Delgado (Delgado 1970, 33), en el que se incluyen un grupo heterogéneo de asas recortadas en hoja de metal, finalizadas en punta más o menos aguzada, lisas o decoradas. Es el tipo de asa más sencilla, por lo que no se pueden ofrecer matizaciones cronológicas, debido a la extensión temporal que las caracteriza.

CAZOS

Núm. 14 (fig. 6, 14).

Procedencia: La Bienvenida (Núm. inv. BV/84/836), depositado en el Museo de Ciudad Real.

Descripción: Cazo de bronce cuya forma es la de un cubilete de paredes rectas, terminado en un pie anular apenas resaltado. Todo el recipiente se decora profusamente. La ornamentación del galbo se divide en cinco bandas, delimitadas por líneas incisas. La banda superior, es decir, la más cercana al borde, tiene incisos una serie de círculos formando un motivo corrido, estando las dos bandas inferiores decoradas mediante puntos impresos sobre las líneas incisas, y estando las otras dos bandas lisas. La pieza se completaba con un mango, del que se ha conservado la unión con el vaso. Dicho mango se restauró de antiguo, sobreponiendo sobre el original otro más grosero, hoy perdido, pero que todavía se puede intuir por los restos de estaño que aún se conservan, adheridos sobre la parte terminal del mango primitivo. Parece haber sido fabricado con molde. Mide $5,4 \mathrm{~cm}$ de diámetro en el borde y $2,2 \mathrm{~cm}$ de alto.

Estudio: Simpulum perteneciente a un grupo, bien definido, de pequeños cazos con galbo de perfil doble cóncavo, correspondientes al tipo 43 de Radnoti (RADNOTI 1938, 102, fig. 8, núm. 43), datados en el siglo I d. C., con posible perduración a principios del siglo siguiente (BOESTERD 1956, 37).

Entre los que presentan ornamentación, destacamos el ejemplar procedente de Millingen (BOESTERD 1956, 36-37, fig. 4, núm. 106), por ostentar una sintaxis decorativa similar al de La Bienvenida, salvo que el motivo seriado que ocupa la franja superior, está confeccionado a base 
de óvalos en vez de círculos. Esquema compositivo idéntico al paralelo anteriormente citado, lo encontramos en un simpulum de Panonia (RADNOTI 1938, lám. 28, núm. 8), y en otro de Magdalensberg fechado en la primera mitad del siglo I d.C. (DeIMEL 1987, 156, fig. 27, núm. 1).

En el solar hispano sólo conocemos una pieza de este tipo, procedente de la necrópolis de Horta das Pinas (PONTE 1986, 122, fig. 32), y carente de decoración.

Núm. 15 (fig. 6, 15).

Procedencia: Antigua colección E. Tello, depositado en el Museo de Ciudad Real.

Descripción: Mango de hierro, realizado a partir de una lámina rectangular recortada. Remata, en uno de sus extremos, por dos apéndices en los que se conservan sendos remaches, y en el otro por un pequeño gancho, usado para colgar la pieza. En la parte central la hoja se dobló sobre sí misma, para conseguir un receptáculo tubular de índole decorativa. Mide $21,4 \mathrm{~cm}$ de longitud máxima.

Estudio: No se han hallado paralelos para este ejemplar. Postulamos su inserción en un recipiente tipo cazo, de fabricación local.

Núm. 16 (fig. 6, 16)

Procedencia: Los Castellones de Ceal (Jaén), en paradero desconocido.

Descripción: Mango de cobre, rematado en su extemo por la estilización de una cabeza zoomórfica. Su parte central está constituida por un cilindro decorado con incisiones. Mide $27 \mathrm{~cm}$ de longitud máxima.

Estudio: El uso de cabezas como remates de mangos se constata desde el vi a.C., en el ámbito de la cultura etrusca. En el período reseñado son utilizadas, preferentemente, las figuras de cisne (TASSINARI 1975, 38, núm. 40 y 41), o de serpiente (BOESTERD 1956, 16, núm. 43), tanto en cazos como en coladores (TASSINARI 1975, 37, núm. 6). Durante la época romana se siguieron empleando las cabezas de pájaro (BOEs- 
Vajilla metálica de época romana en los museos de Ciudad Real, ...
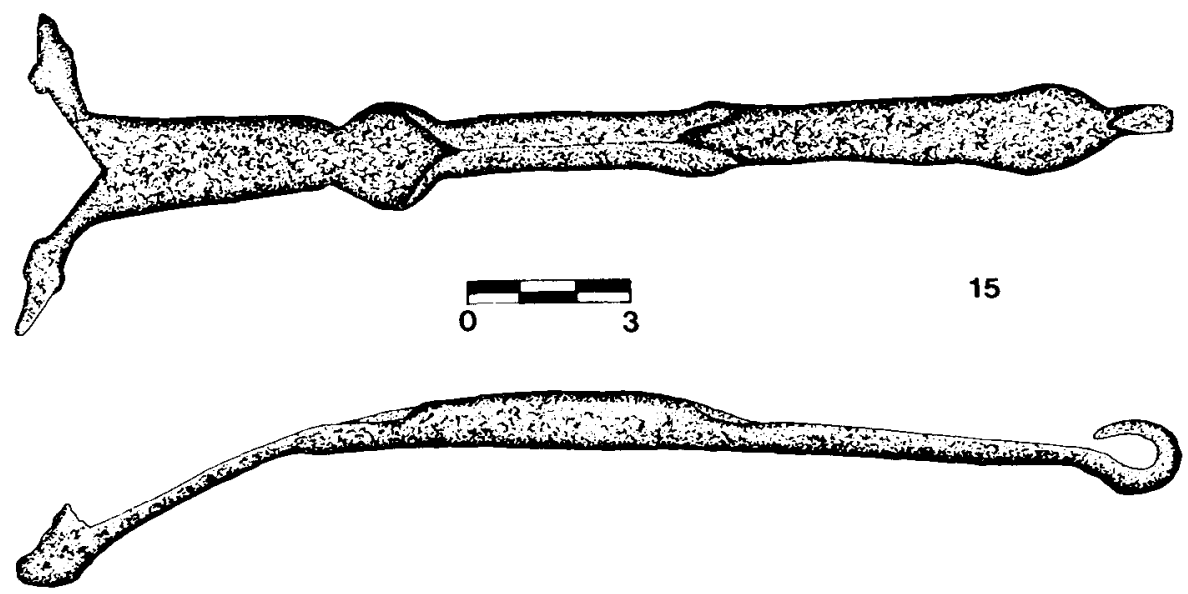

\section{$16 \mathrm{~S} / \mathrm{E}$}
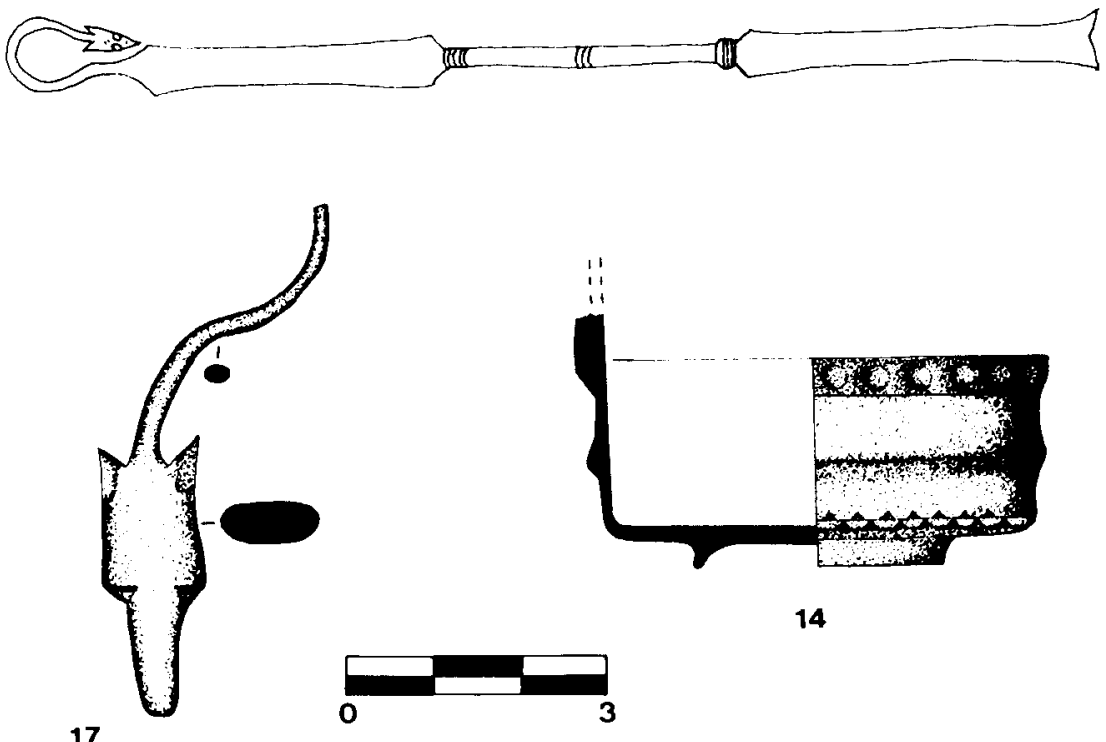

Fig. 6: Núm. 14: Cazo de La Bienvenida (Ciudad Real).

Núm. 15: Mango del Museo de Ciudad Real.

Núm. 16: Mango de Los Castellones de Ceal (Jaén).

Núm. 17: Remate de mango del Museo de Linares. 
TERD 1956, 34, núm. 96), introduciéndose, ahora, las de lobo, reservadas estas últimas especialmente para los simpula (TASSINARI 1975, 40, núm. 46).

Respecto a la cronologia, no parece que los ejemplares naturalistas rebasen el siglo I d.C., pudiendo perdurar las representaciones más estilizadas, hasta comienzos de la centuria siguiente.

El mango de Los Castellones encajaria dentro de la producción romana del siglo । d.C., manifestando contactos evidentes con piezas procedentes de Panonia. En Brigetio se halló un simpulum, cuyo asidero presenta una decoración de incisiones, en la parte cilindrica, distribuida del mismo modo que en el caso que nos ocupa (RADNOTI 1938, lám. 28, núm. 4), compartiendo también la forma general de la pieza.

En Hispania encontramos otro ejemplar muy semejante al que tratamos, perteneciente a Castelo da Lousa (Do PACO 1966, 179, fig. 12, núm. 28) e inscrito en un contexto arqueológico del siglo I a.C.-siglo I d.C (Do PACO 1966, 182). Finalmente, queremos reflejar un último simpulum, que a pesar de corresponder a un tipo distinto (derivado del tratamiento realista de la cabeza terminal y el ser de plata), tiene interés por su adscripción al territorio giennense; nos referimos al cazo del tesoro de Menjibar (Álvarez 1945, 288).

Núm. 17 (fig. 6, 17)

Procedencia: Desconocida, depositado en el Museo de Linares (núm. inv. 347-353).

Descripción: Fragmento de mango de un simpulum que remata en la estilización de una cabeza de animal. Fundición en molde. Mide $6,2 \mathrm{~cm}$ de longitud máxima y $1,2 \mathrm{~cm}$ de ancho máximo.

Estudio: Pertenece a un mango del mismo tipo que el inventariado con el número anterior, por lo que sólo reseñaremos una pieza muy parecida hallada en Vienne (BOuCHER 1971, 169, núm. 377). Boucher interpreta la cabeza terminal del paralelo citado, como perteneciente a un cánido. 


\section{CONCLUSIONES}

A través de este catálogo, hemos constatado una amplia muestra representativa de la vajilla metálica en la Oretania romana. Los resultados individuales ofrecidos por cada pieza, nos sirven de base para la elaboración de unas conclusiones generales que pasaremos a exponer.

A efectos metodológicos, nos parece oportuno matizar nuestras conclusiones en torno a algunos parámetros básicos, entre los que destacan la tipología, el origen de las piezas y su cronologia. Refiriéndonos a la cronología indicaremos, a priori, que la temporalidad de piezas desprovistas de contexto siempre constituye un tema de dificil solución. A lo largo del catálogo, hemos ido dotando de marco cronológico a la mayoría de los ejemplares presentados, consiguiéndolo mediante la comparación con paralelos. Somos conscientes de que esto supone un riesgo ya que, en ocasiones, no se pueden extrapolar los datos aportados por objetos pertenecientes a otras áreas geográficas. En el caso concreto de los productos hispanorromanos, esta cuestión sólo podrá solucionarse cuando contemos con una serie de excavaciones con estratigrafias, en las que iremos encajando los distintos objetos que conforman la cultura material metálica de nuestro territorio.

Consideramos, también, que para las producciones metálicas hispanas, sería básico señalar las corrientes de influencia que originaron el surgimiento de creaciones peninsulares propias, pero que están inmersas en la unidad tipológica del Imperio, de la que sólo se desvían en algunas peculiaridades. En otras palabras, muchos de nuestros ejemplares se encuentran incluidos dentro de un lenguaje conceptual existente en otras áreas del Imperio, si bien los resultados finales se presentan aquí con personalidad propia. Puede intuirse que los recipientes metálicos oretanoromanos responden a un proceso de adopción de la idea primigenia, así como a una posterior reinterpretación local de modelos con circulación paralela en otras provincias. Ahora bien, ¿de dónde proceden los modelos iniciales? En la actualidad estas influencias no pueden ser fijadas con rigor, ya que faltan en las publicaciones científicas muchos de los materiales procedentes de Italia. Este vacio es de suma importancia, pues Italia es el punto de origen de las producciones provinciales.

$\mathrm{El}$ inventario aquí presentado demuestra la riqueza morfológica de la vajilla oretana, en la que están representadas muchas de las formas características del mundo romano. Un punto sustancial es el origen geográfico de los ejemplares. Para algunos de ellos, hemos fijado con seguridad su centro de fabricación fuera de nuestras fronteras, pero cierta- 
mente los objetos importados son minoritarios. Los materiales itálicos están representados por los cubos "östland" (números 3 y 4) (siglos I-II d. C.) y los cuencos de plata (números 1 y 2) (siglo I a. C.). El pequeño simpulum de La Bienvenida (número 14) (siglo । d. C.), podría también estar conectado con este círculo. Estas importaciones se insertan en los momentos iniciales del Imperio, fenómeno parejo a lo que ocurre en otras provincias. Posiblemente al grupo provincial galo-romano, pertenecen las jarras «blechkannen» constatadas en la región (números, 8, 9 y 10).

Para el resto de los materiales, podemos considerar aquellos que son claramente productos hispanos y los que no están adscritos a un área concreta, pero que, posiblemente, estos últimos halla que añadirlos a la lista de las mal conocidas producciones peninsulares. Resulta significativo que en el área geográfica que nos ocupa, concretamente en La Bienvenida-Sisapo se constante la actividad metalistera. En este yacimiento de Ciudad Real no sólo aparecen útiles relacionados con este trabajo (buriles, cortafríos, barrenas), sino también escorias de fundición y materiales de desecho, como son recortes de láminas y recipientes troceados (AURRECOECHEA et alii 1986, 276, fig. 8, núm. 1).

Un apartado importante, al hablar de las producciones hispanorromanas, son los apliques de situla. Coincidimos con Delgado en la reivindicación de un carácter especificamente hispano para los grupos "l» y "IV» de su tipología, una vez comprobada su total ausencia en esquemas foráneos y su dispersión en la Península. Representantes de ambos tipos los encontramos en el yacimiento oretano de La Bienvenida (AURRECOECHEA Y ZARZALEJOS 1990, fig. 1, núm. 1 y 2). También hispana podría ser la variante Al, para la que contamos con un ejemplar en Cástulo (AURRECOECHEA Y ZARZALEJOS 1990, fig. 2, núm. 4). El marco temporal al que parecen ceñirse estas creaciones hispanas iniciales, se sitúa entre el siglo II-ill d. C.. A esta misma cronología apunta otro espécimen, no recogido en la clasificación de Delgado, que ostenta una placa en forma de hoja de parra decorada con el rostro de un efebo (AURRECOECHEA Y ZARZALEJOS 1990, lám. 1). De época tardorromana y carácter hispánico sería el tipo II de Delgado, al que está adscrito el especimen del Castro de la Magdalena, cuya datación habria que prolongar desde finales del siglo III hasta el siglo $v$ d.C. (AuRRECOECHEA $Y$ ZARZALEJOS 1990, fig. 2, núm. 1).

Continuando con las producciones pertenecientes a talleres hispanos, hemos de destacar la lagoena de Plaza de Armas (número 7) (siglos III-IV d. C.) y la pátera de La Bienvenida (siglo IV-V d. C.) (AURRECOECHEA 1989, 840-842, fig. 1), como características de un mundo bajoimperial. Su conexión con la tipología de recipientes tardíos promulgada 
por Palol, y en concreto con las variantes ofertadas por Caballero Zoreda, vienen a enriquecer la ya larga lista de materiales de esta época, sin duda alguna, la mejor conocida en los ambientes científicos. Incidimos, en la posible relación existente entre las jarras hispánicas de este momento (tipo 11) y las "blechkannen" coetáneas europeas, como un elemento novedoso de suma importancia, para delimitar otro rasgo característico de la cultura tardía en Hispania. La bandeja encontrada en Cástulo podría encuadrarse, asimismo, en esta fase temporal. (BLÁZQUEZ 1984, 48 y 51 , fig. 22, núm. 77 ).

Fuera de toda adscripción concreta, quedarian la mayoria de los recipientes vinculados con el ajuar doméstico de la casa. Para ellos, también reivindicamos su carácter hispánico, aunque su vinculación a talleres concretos la consideramos muy difícil. Ello se debe a que, generalmente, son productos elaborados por artesanos locales de forma individual o en reducidas asociaciones, comercializados a pequeña escala por comerciantes ambulantes que distribuian la mercancia. En otros casos, pudieron estar fabricados por obradores, que trabajaban al servicio de una explotación económica del tipo villa. La serie más numerosa de recipientes, encuadrables en estos términos, son las sítulas. De hierro son las dos halladas en Plaza de Armas (números 11 y 12), broncíneas las de La Bienvenida (AuRRECOECHEA et alii 1986, 267, fig. 5, núm. 1 y 5) y conjuntando ambos metales la de Cástulo (BLAZQUEZ 1984, 48 y 51, fig. 21, núm. 80). La bandeja, encontrada en la estación sisaponense, junto a la cacerola y los recipientes de hierro de uso indeterminado, de este mismo yacimiento (AuRRECOECHEA et alii 1986, fig. 7, núm 1; fig. 6, núm. 3 y 4 ; fig. 4, núm. 5), completarian el ajuar que exponemos.

Por último, respecto a la funcionalidad de los recipientes, hemos constatado una menor representación de la vajilla destinada al servicio de mesa. A este fin, aparte de las jarras, sólo encontramos vinculado el vaso depositado en el Museo de Linares (número 5) y los restos de cazos catalogados (números 14, 16 y 17). 


\section{REFERENCIAS BIBLIOGRÁFICAS}

Alarcao, J. (1979): Fouilles de Conímbriga. Tomo VII. Trouvailles diversesConclusions Générales. Paris.

Alvarez Osorio, F. (1954): "Tesoros españoles antiguos en el MAN", Boletín de la Real Academia de la Historia, 134.

AURRECOECHEA, J. et alii (1986): "Mobiliario metálico del yacimiento iberoromano de La Bienvenida, en la provincia de Ciudad Real», Oretum, 2.

- (1989): “Páteras romanas de la Bienvenida (Almodóvar del Campo, Ciudad Real)", Congreso Nacional de Arqueología, 19. Zaragoza.

AURRECOECHEA, J., y ZARZALEJO, M. (1990): «Apliques de sítula de la Oretania romana. Algunas matizaciones a la tipología de Delgado", Archivo Español de Arqueología, 63.

BELTRÁN FORTES, J. et alii (1989): “Algunos bronces figurados de la provincia de Jaén", Congreso Nacional de Arqueología, 19. Zaragoza.

BLÁZQUEZ, J. M. (1960): “Recipientes de bronce del Museo Arqueológico Nacional de Madrid", Archivo Español de Arqueologia, 33.

- (1981): Mosaicos romanos de Córdoba, Jaén y Málaga. Corpus de mosaicos de España, III. Madrid.

- et alii (1984): "Cástulo, IV», Excavaciones Arqueológicas en España, 131.

Boersterd, M. H. P. (1956): The bronze vessels in the Rijkmuseum G. $M$. at Nimegen. Minyer.

BOUCHER, S. (1975): Vienne. Bronzes antiques. Inventaire des collections publiques françaises, 17.

Boucher, S. y TASSINARI, S. (1976): Bronzes Antiques du Musée de la civilisation gallo-romaine a Lyon. I: Inscriptions, statuaire et vaiselle. Lyon. 
Vajilla metálica de época romana en los museos de Ciudad Real, ...

Caballero, A., y Fernández Ochoa, C. (1981): «El yacimiento romano de La Bienvenida, Almodóvar del Campo (Ciudad Real)", Cuadernos de Estudios Manchegos, 11.

CABALleRoZOREDA, L. (1974): “La necrópolis de Fuentespreadas (Zamora)», Excavaciones Arqueológicas en España, 80.

DA PONTE, S. (1986): “Algunas peças metálicas de necrópoles romanas dos distritos de Portalegre e de Evora", Conimbriga, 25.

De Albuqueroue e CAStro, L. (1962): «Hallazgos romanos en la mina Do Fojo das Pombas (Valongo-Portugal)", Archivo Español de Arqueología, 35.

DeIMEL, M. (1987): Die Bronzekleinfunde vom Magdalensberg. Klagenfurt.

Del NIDO, R. (1964-65): «Edificaciones romanas en el cortijo Plaza de Armas, del pago de Bruñel», Noticiario Arqueológico Hispánico, 8-9.

Delgado, M. (1970): «Elementos de sítulas de bronze de Conimbriga», Conímbriga, 9.

Do PAÇO, A., y BAÇAO, J. (1966): “Castelo da Lousa, Mourás (Portugal). Una fortificación romana de la margen izquierda del Guadiana», Archivo Español de Arqueología, 39.

DREXEL, F. (1909): "Alejandrinische Silbergefässe der Kaiserzeit», Bonn $J h b ., 118$.

EGgERS, H. J. (1951): Das römische Import in freien Germanien. Hamburgo.

EsCORTELL, M. (1975): Catálogo de las salas de cultura romana del Museo Arqueológico de Oviedo. Oviedo.

Faider-Feytmans, G. (1979): Les bronzes romains de Belgique. Mainz.

Fernandez CAStro, M. C. (1982): Villas romanas en España. Madrid.

Fernández ChICARRO, C. (1956): «Prospección arqueológica en los términos de Hinojares y La Guardia (Jaén)", Boletín del Instituto de Estudios Gienenses, 7.

FERNÁNDEZ OCHOA, C. et alii (1982-83): "Nuevo documento epigráfico para la localización de Sisapo", Cuadernos de Prehistoria y Arqueología de la Universidad Autónoma de Madrid, 9-10.

Fernández Ochoa, C. y Caballero, A. (1988): «El horizonte histórico de la Bienvenida y su posible identificación con la antigua Sisapo", $1^{\text {er }}$ Congreso de Historia de Castilla-La Mancha, tomo IV. Romanos y visigodos: Hegemonía cultural y cambios sociales.

FREMERSDORF, F. (1933): “Der römische Gutshof Köln-Müngersdorf», Römisch-Germanische Forschungen, 6.

FUENTES, A. (1980): Panorama de la arqueología tardorromana en la provincia de Cuenca, Memoria de Licenciatura de la U.A.M. Inédita.

Garcia y BelLIDO, A. (1949): Esculturas romanas de España y Portugal. Madrid.

Goudineau, C. (1981): “Circonscription de Côte d’Azur», Gallia, 39. 
HEINZ, K. (1979-80): “Östlandeimer aus dem Nniederwesergebiet» Fundberichte aus Hessen, Jahrgang, 19-20.

HILGER, W. (1969): Lateinische Gefässnamen, Bezeichnungen, Funktion und Form römischer Gefässe nach den antiken Schriftquellen. Düsseldorf.

Kaufmann-Heinimann, A. (1977): Die römischen bronzen der Schweiz. August. Mainz.

LeIBUNDGUT, A. (1980): Die römischen bronzen der Schweiz. III. Westschweiz bern und wallis. Mainz.

MALUQUER DE MOTES, J. (1968): «Excavaciones arqueológicas en el castro de Las Merchanas (Lumbrales, Salamanca), Pyrenae, 4.

MARQUes, G. (1969): "O poço de estaçaô romana de Torre dos Namorados (Fundâo)", Conimbriga, 8.

MENZEL, M. (1966): Die römischen bronzen aus Deutschland II. Trier.

- (1986): Die römischen bronzen aus Deutschland III. Bonn.

MILLER, K. (1884): Die römischen Begräbnisstätten im Württemberq.

MONTEVERDE, L. (1945): "Sobre la necrópolis romana de Hornillos del Camino (Burgos)", Archivo Español de Arqueologia, 18.

Nogales, T. (1990): "Bronces romanos en Augusta Emerita", Catálogo de la exposición Los bronces romanos en España. Madrid.

OlIVER, A. (1977): Silver for the Gods. 800 years of Greek and Roman Silver. Toledo, Ohio.

ORENSANZ, F. (1971-72): “Notas sobre materiales arqueológicos aragoneses de época ibero-romana», Caesaraugusta, 35-36.

PALOL, P. DE (1970): “Necrópolis hispanorromanas del siglo IV en el valle del Duero. Los vasos y recipientes de bronce", Boletín del Seminario de Arte y Arqueología, 36.

PALOL, P. DE y SOTOMAYOR, M. (1972): «Excavaciones en la villa romana de Bruñel (Quesada), en la provincia de Jaén", Actas del VIII Congreso de Arqueología Cristiana. Ciudad del Vaticano-Barcelona.

RADNOTI, A. (1938): Die römischen Bronzegefässe von pannoniem. Dissertationes Pannonicae. Budapest.

RAEV, B. (1976): "Les blechkannen de province et leur prototypes italiques", Actes du IV Colloque International sur les bronzes antiques.

Annales d l'universite Jean Moulin.

Rosas ARTOLA, M. (1980): «El mobiliari metál-lic del poblat ibero-romá de Sant Josep (La Vall D'Uixo, Castelló)", Cuadernos de Prehistoria y Arqueologia Castellonenses, 7.

SAKAR, V. (1970): “Roman imports in Bohemia», Fontes archaeologici pragenses, 14.

StRONG, D. F. (1966): Greek and Roman gold and silver plate. Londres. 
Vajilla metálica de época romana en los museos de Ciudad Real, ...

TASSINARI, S. (1975): “La vaiselle de bronze romaine et provinciale au Musee des Antiquites nationales", Suplemento a Gallia, 29.

Thouvenot, R. (1927): Cataloque des figurines et objets de bronze du Musée Archéologique de Madrid, I. Les Bronzes grecs et romaines", Bibliotheque de l'Ecole des Hautes Etudes Hispaniques, 12. Paris.

URTEAGA, M. (1988): "Los bronces romanos de Higer. Hondarribia. Guipuzkoa", Munibe, 40.

WALTERS, H. B. (1921): Cataloque of the silver plate (greek, etruscan and roman) in the British Museum. Londres.

WEECK, W. (1932): «Ein reiches alamannisches Frauengrab aus Täbingen (OA. Rottweil)", Germania, 16. 